\begin{tabular}{ll} 
AL-MUDARRIS & $:$ journal of education, Vol. 2, No. 2 Oktober 2019 \\
Homepag & $:$ http://e-journal.staima-alhikam.ac.id/index.php/al-mudarris \\
\hline ISSN & $: 2620-5831$ (print), ISSN: 2620-4355(online) \\
DOI & $: 10.32478 /$ al-mudarris.v\%vi\%i.263 \\
Article type & $:$ Original Research Article
\end{tabular}

\title{
PENGEMBANGAN MEDIA PEMBELAJARAN ILMU PENGETAHUAN ALAM BERBASIS SWISHMAX DI MIN 2 PALEMBANG
}

\author{
Dispi Riska*1, Muhamad Afandi*2, Mardiah Astuti*3 \\ Program Studi PGMI, Fakultas Ilmu Tarbiyah dan Keguruan, \\ UIN Raden Fatah Palembang, Indonesia \\ ${ }^{1}$ dispiriska21@gmail.com, ${ }^{2}$ muhammadafandi_uin@radenfatah.ac.id, \\ ${ }^{3}$ mardiahastuti_uin@radenfatah.ac.id
}

\begin{abstract}
The purpose of this study was to determine the level of validity, practicality and effectiveness of the development of Swishmax-based Natural Sciences learning media in IVG MIN 2 Palembang. This research method uses Research and Development (R \& D) methods. The research and development model used is the tressmer model with the stages of research: the preliminary stage (preparation and design), the formative evalution stage (self evaluation, expert review, one to one, small group, and field test). Data collection techniques using questionnaires and tests. Data analysis techniques use percentages. The results of this study include: (1) Development of Swishmax-based Natural Sciences learning media in Palembang IVG MIN 2 Class can be categorized as valid. This is indicated by the acquisition of media expert validation scores of 84.5 , language experts 82 , and material experts 90 ; (2) The practicality level of the application of the development of Swishmax-based Natural Sciences learning media in Palembang IVG MIN 2 Class is very practical. This can be seen from the acquisition of the average questionnaire score of 100 in the field test stage; (3) The effectiveness of the development of Swishmax-based Natural Sciences learning media in Palembang IVG MIN 2 Class is very effective. It is known that the level of mastery learning in classical students reaches $95 \%$ in the field test stage.
\end{abstract}

Keywords: Learning Media, Swishmax, SD/MI Science

E-mail address: ${ }^{1}$ dispiriska21@gmail.com, ${ }^{2}$ muhammadafandi_uin@ $@$ radenfatah.ac.id, 3mardiahastuti_uin@radenfatah.ac.id

186 Peer reviewed under reponsibility of STAI Ma'had Aly Al-Hikam Malang

186 C2019 STAI Ma'had Aly Al-Hikam Malang, All right reserved, This is an open access article under (c) (i) (2)

This work is licensed under a Creative Commons Attribution-ShareAlike 4.0 International License. 


\begin{abstract}
Abstrak
Tujuan penelitian ini adalah untuk mengetahui tingkat validitas, kepraktisan, dan efektivitas pengembangan media pembelajaran Ilmu Pengetahuan Alam berbasis Swishmax di Kelas IVG MIN 2 Palembang. Metode penelitian ini menggunakan metode penelitian dan pengembangan atau Research and Development (R\&D). Model penelitian dan pengembangan yang digunakan adalah model tressmer dengan tahap-tahap penelitian: tahap preliminary (persiapan dan pendesainan), tahap formative evalution (self evalution, expert review, one to one, small group, dan field test). Teknik pengumpulan data menggunakan angket dan tes. Teknik analisis data menggunakan persentase. Hasil penelitian ini antara lain: (1) Pengembangan media pembelajaran Ilmu Pengetahuan Alam berbasis Swishmax di Kelas IVG MIN 2 Palembang dapat dikategorikan valid. Hal ini ditunjukkan dari perolehan skor validasi ahli media sebesar 84,5, ahli bahasa 82, dan ahli materi 90; (2) Tingkat kepraktisan penerapan pengembangan media pembelajaran Ilmu Pengetahuan Alam berbasis Swishmax di Kelas IVG MIN 2 Palembang sangat praktis. Hal ini dapat diketahui dari perolehan rata-rata skor angket sebesar 100 pada tahap field test; (3) Efektivitas pengembangn media pembelajaran Ilmu Pengetahuan Alam berbasis Swishmax di Kelas IVG MIN 2 Palembang sangat efektif. Hal tersebut diketahui dari tingkat ketuntasan belajar peserta didik secara klasikal mencapai $95 \%$ pada tahap field test.
\end{abstract}

Kata kuci: Media Pembelajaran, Swishmax, IPA SD/MI

\title{
A. PENDAHULUAN
}

Media merupakan perantara yang digunakan sebagai alat bantu dalam mengajar. Media sangat beragam jenisnya seiring dengan kemajuan teknologi saat ini. Pemnafaatan media dalam pembelajaran dapat dimanfaatkan sesuai dengan kondisi, waktu, keuangan, maupun materi yang akan disampaikan.Media memiliki kontribusi yang penting dalam meningkatkan kualitas dan mutu proses pembelajaran. ${ }^{1}$ Inovasi

\footnotetext{
${ }^{1}$ Cecep Kustandi, Media Pembelajaran Manual dan Digital, (Bogor: Ghalia
} Indonesia, 2011), h. 1 
pembelajaran mutlak diperlukan seiring perubahan dan perkembangan teknologi baik dalam arti perangkat keras, perangkat lunak maupun teknologi lainya dalam pembelajaran. ${ }^{2}$ Poin penting yang wajib dan harus guru perhatikan dalam pemanfaatan teknologi sebagai media pembelajaran adalah keterseidaan hardware dan software serta bentuk metode pembelajaran yang akan digunakan. ${ }^{3}$

Beberapa penelitian sebelumnya yang membahas tentang pengembangan media diantaranya pengembangan media pembelajaran android oleh Abu Yazid Bustomi ${ }^{4}$, Resti Yektyastuti , Jaslin Ikhsan ${ }^{5}$. Pengembangan media pembelajaran berbasis ICT oleh Aquami, Muhamad Afandi, Andi Putra Sairi ${ }^{6}$, tentang efektifitas media audiovisual oleh Septo Haryoko ${ }^{7}$, Arif Wahyudi, Suhartono, dan Ngatman ${ }^{8}$. Yang membahas tentang pengembangan media swishmax pada siswa SMA oleh Purbo Suwasono Kharisma Resi Pradipta, Widjianto ${ }^{9}$, Iwan

${ }^{2}$ Pujiriyanto, Teknologi Pengembangan Media dan Pembelajaran, (Jakarta: Raja Grafindo, 2012), h. 56

3 Aquami, Muhamad Afandi, Andi Putra Sairi, Pengembangan Media Pembelajaran Berbasis ICT Menggunakan Macromedia Flash Pada Mata Pelajaran IPA MI/SD, Al-Mudarris Journal of Education, Volume 2, Nomor 1, April 2019, h. 53-78, https://doi.org/10.32478/al-mudarris.v2i1.194

${ }^{4}$ Abu Yazid Bustomi, 'Aplikasi Pembelajaran Panca Indra Pada Manusia Berbasis Android', Telematika, 3.1 (2010), 25-36.

5 Jaslin Ikhsan Resti Yektyastuti, 'Pengembangan Media Pembelajaran Berbasis Android Pada Materi Kelarutan Untuk Meningkatkan Performa Akademik Peserta Didik SMA Developing Android-Based Instructional Media of Solubility to Improve Academic Performance of High School Students', Jurnal Inovasi Pendidikan IPA, 2.1 (2016), 88-99 <https://doi.org/10.21831/jipi.v2i1.10289>.

${ }^{6}$ Aquami, Muhamad Afandi.

7 Sapto Haryoko, 'Efektivitas Pemanfaatan Media Audio-Visual Sebagai Alternatif Optimalisasi Model Pembelajaran', Jurnal Edukasi@Elektro, 5.1 (2010), 110 .

8 Arif Wahyudi, Suhartono, and Ngatman, 'Penggunaan Media Audio Visual', Jurnal Penelitian Pendidikan, 2003.

${ }^{9}$ Purbo Suwasono Kharisma Resi Pradipta, Widjianto, 'PENGEMBANGAN MEDIA PEMBELAJARAN FISIKA BERBASIS MULTIMEDIA DENGAN SWISHMAX 4 PADA MATERI KINEMATIKA GERAK LURUS UNTUK SISWA SMA', 2016, 13. 
AL-MUDARRIS:journal of education, Vol. 2. No. 2 Oktober 2019, ISSN: 2620-5831 (print), ISSN: 2620-4355(online)

DOI: $10.32478 /$ al-mudarris.v\%vi\%i.263

Kurniawan, Siti Kholifah. ${ }^{10}$ Berbeda dengan penelitian sebelumnya, penelitian ini bertujuan untuk mengetahui tingkat validitas, kepraktisan, dan efektivitas pengembangan media pembelajaran Ilmu Pengetahuan Alam berbasis Swishmax di Kelas IVG MIN 2 Palembang.

Telah banyak berbagai software yang dapat dimanfaatkan untuk mengembangkan media pembelajaran. Guru harus tahu dan mampu menggunakan teknologi serta mampu berkreatifitas memanfaatkan teknologi dari berbagai macam software/aplikasi yang ada. Aplikasi atau software yang dapat dimanfaatkan untuk mengembangkan media pembelajaran yaitu aplikasi Swishmax. Swishmax merupakan aplikasi untuk membuat animasi flash seperti halnya macromedia flash MX. Format dasar Swishmax adalah swis file, namun dapat juga dieksor kedalam file flash (swf), movie (avi), ataupun execute (exe) program yang dapat dijalankan berdiri sendiri. ${ }^{11}$

Berdasarkan hasil observasi pada hari Senin tanggal 12 November 2018, fasilitas-fasilitas di MIN 2 Palembang sangat memadai dan menunjang kegiatan pembelajaran dan sebagian guru di MIN 2 Palembang dalam proses pembelajaranya sudah menggunakan media ICT seperti proyektor dan media Power Point khususnya pada kelas IVG. Namun dalam proses pembelajaran masih banyak siswa yang belum termotivasi dalam pembelajaran tersebut yang disebabkan media tersebut kurang menarik karena terlalu banyak tulisan yang ditampilkan sehingga slide tersebut menjadi penuh, dan teks pun menjadi kecilkecil. Guru pun tidak menggunakan visualisasi seperti gambar, audio, animasi serta video yang berkaiatan tentang materi yang akan diajarkan.

Berdasarkan analisis kebutuhan di atas, dapat diasumsikan bahwa pembelajaran di kelas IVG MIN 2 Palembang memerlukan media pembelajaran yang mampu menciptakan proses belajar yang menyenangkan, menarik, interaktif serta efektif. Khususnya untuk IPA

${ }^{10}$ Iwan Kurniawan, Siti Kholifah, 'PENGEMBANGAN MEDIA VIDEO PEMBELAJARAN BERBANTUAN SOFTWARE SWISHMAX DAN SCREENCAST O-MATIC DENGAN MODEL FLIPPED CLASSROOM PADA MATA KULIAH MANAJEMEN STRATEGIK', NUSAMBA, 1.2 (2016), 21-26.

11 Munir, Pembelajaran Jarak Jauh Berbasis Teknologi Informasi dan Komunikasi, (Bandung: Alfabeta, 2012), h. 90 
di SD/MI hendaknya membuka kesempatan untuk memupuk rasa ingin tahu peserta didik secara alamiah. Pembelajaran IPA harus mampu membangkitkan minat siswa agar dapat meningkatkan kecerdasan dan pemahamannya tentang alam dan seisinya. ${ }^{12}$

Salah satu media pembelajaran yang dapat dikembangkan yaitu media pemelajaran berbasis Swishmax. Media pembelajaran berbasis Swishmax ini dapat mengurangi suasana yang statis dan dapat menciptakan proses pembelajaran yang efektif, menarik, interaktif dan menyenangkan. Selain itu media pembelajaran berbasis Swishmax bisa digunakan oleh siswa itu sendiri, dengan kata lain siswa bisa belajar secara mandiri baik di rumah maupun dalam kelompok belajar yang dibentuk oleh siswa sendiri. Hal ini dapat meningkatakan tingkat pemahaman belajar siswa. ${ }^{13}$

\section{B. KAJIAN TEORI}

Swishmax merupakan aplikasi untuk membuat animasi flash seperti halnya macromedia flash MX. Format dasar Swishmax adalah swis file, namun dapat juga diekspor kedalam file flash (swf), movie (avi), ataupun execute (exe) program yang dapat dijalankan berdiri sendiri. Swishmax sangat mudah untuk membuat animasi dalam bentuk teks, gambar, grafik dan suara dengan waktu yang cepat. Swishmax memiliki 230 efek siap pakai seperti Explode, Vortex, Snakes dan lainlain. Swishmax memiliki tools untuk menggambar garis, rectangels, elips, kurva acak, motion path, sprites, tombol dan form masukan dengan cara yang lebih mudah. Komponen Swishmax memiliki

${ }^{12}$ Nunung Dwi Setiyorini, Pembelajaran Kontekstual IPA Melalui Outdoor Learning di SD Alam Ar-Ridho Semarang, Al-Mudarris Journal of Education, Volume 1, Nomor 1, April 2018, h. 30-38, https://doi.org/10.32478/almudarris.v1i1.97

13 Yeka Hendriani, Vera Irma Delianti, Lativa Mursyida, Persepsi Penggunaan SWiSHmax untuk Pengembangan Media Pembelajaran Oleh Guru Sekolah Dasar di Gugus 3 Kamang Magek Kabupaten Agam, Jurnal Teknologi Informasi dan Pendidikan, Volume 10, Nomor 3, Oktober 2017, h. 101-106 
AL-MUDARRIS:journal of education, Vol. 2. No. 2 Oktober 2019, ISSN: 2620-5831 (print), ISSN: 2620-4355(online)

DOI: $10.32478 /$ al-mudarris.v\%vi\%i.263

berbagai macam fungsi dan fasilitas yang mendukung dalam pembuatan Animasi Flash ataupun sebuah media pembelajaran. ${ }^{14}$ berikut: ${ }^{15}$

Adapun kelebihan dan kekurangan software Swishmax sebagai

a. Kelebihan Software Swishmax

1) Swishmax relatif lebih mudah digunakan dibandingkan macromedia flash dan dengan hasil relatif sama Swishmax sudah dilengkapi dengan berbgai animasi yang menarik dan mudah dalam penggunaanya.

2) Swishmax dapat menstimulasikan efek gerak. Dapat diberi suara dan warna.

3) Dapat mendesain konten pelajaran menjadi lebih kreatif dan inovatif

4) Swishmax juga mampu menangani link antar objek maupun dokumen.

5) Swishmax juga dapat melakukan import file animasi seperti animasi flash.

b. Kekurangan Software Swishmax

1) Memerlukan peralatan khusus dalam penyajian.

2) Memerlukan keterampilan khusus dalam pembuatan.

3) Memerlukan tenaga listrik.

Langkah-Langkah dalam membuat media pembelajaran dengan software atau program Swishmax yaitu sebagai berikut:

a. Menginstal swishmax

1) Klik dua kali file setup untuk menjalankan swishmax.exe

2) Klik pada tombol berikutnya atau next, setelah itu akan muncul format pejanjian lisensi aplikasi, klik agree atau setuju dan berikutnya akan muncul tempat untuk menginstall aplikasi.

14 Yeka Hendriani, Vera Irma Delianti, Lativa Mursyida, Persepsi Penggunaan..., h. 101-106

${ }^{15}$ Deni Erlansyah, Pemanfaatan Multimedia Interaktif Konsep Usaha dalam Pelajaran Fisika Berbasis Teknologi Informasi, Jurnal Ilmiah MATRIK, Volume 17, Nomor. 3, Desember 2015, h. 215-226 
3) Klik tombol browse jika ingin menginstall aplikasi ditempat lain, dan klik tombol next jika ingin menginstall aplikasi ditempat yang telah tersedia pada direktori

4) Hilangkan centang pada launch, kemudian tekan tombol close.

b. Cara mengaktifkan Swishmax

Klik menu start-programs-Swishmax-Swishmax. Untuk tampilan awal yang kosong pilih start a new empty movie. Main Menu merupakan menu pilihan utama untuk mengoperasikan Swishmax yang terdiri dari menu file, edit, view, insert, modify, control, tools, panels dan help. Untuk mengakses menu-menu utama tersebut gunakan toolbar. Tools merupakan perintah (command) yang akan menentukan apa yang akan dilakukan swish saat proses click atau drag pada workspace. Perintah itu antara lain select, line, pencil dan lain-lain. Toolbar tersebut terdiri dari:

1) Standar Toolbar untuk pengoperasian file seperti new, open, save.

2) Insert Toolbar untuk memasukkan objek seperti scene, text, image.

3) Control Toolbar untuk mengontrol scene seperti play, stop, play scene.

4) Grouping Toolbar untuk menggabungkan objek seperti group as group.

5) Export Toolbar untuk mengekspor scene seperti export to swf.

c. Membuat Animasi Tulisan

1) yang pertama buatlah terlebih dahulu text/tulisan yang anda ingin buat, dengan cara klik insert dan pilih text yang berada di paling atas form/scane.

2) jika ingin mengetik sebuah tulisan, edit terlebih dahulu tulisan yang anda ingin buat dengan cara mengganti tulisan text yang berada sebelah kanan form / scane contoh : Mengganti tulisan text menjadi "AKU",dan disana juga anda dapat mengganti besar huruf tulisan, warna tulisan dll.

3) Setelah terbuat, anda dapat memberikan animasi pada tulisan ini dengan cara : klik add effeck kemudian pilih animasi yang anda inginkan, Contoh : klik add effeck > explode.Setelah Anda memilih 
AL-MUDARRIS:journal of education, Vol. 2. No. 2 Oktober 2019, ISSN: 2620-5831 (print), ISSN: 2620-4355(online)

DOI: $10.32478 /$ al-mudarris.v\%vi\%i.263

animasi yang telah anda pilih, anda dapat mencoba menjalankannya, dengan cara klik play.

d. Membuat Animasi Teks

1) Klik menu insert text, kemudian ketik text tulisan sesuai dengan keperluan

2) Untuk mengatur model, ukuran, dan warna font klik di jendela propertis

3) Untuk membuat tulisan/teks berikutnya, klik kembali menu: insert text

4) Untuk membuat efek animasi pada teks, klik teks, klik kanan, klik menu effect - core effect - transform.

5) Selanjutnya gambar panel timeline dengan efek transform akan muncul

6) Durasi efeks transform tersedia dalam 20 frame, dapat diubah pada menu propertis klik kanan text efek pada panel timeline

7) Ubah durasi efek transform sesuai keperluan

8) Untuk teks berikutnya lakukan dengan cara yang sama beri efeks squeeze, dengan cara klik teks, klik kanan, pilih menu: effect-core effect-squeeze.

9) Hasil akhirnya dapat dilihat dengan cara klik menu control - test movie. Untuk keperluan lainnya, seperti pembuatan media dan website, file dieksport dulu, klik menu file-export- swf-file name: animasiA-save. $^{16}$

\section{METODE PENELITIAN}

Metode penelitian yang digunakan dalam penelitian ini adalah penelitian dan pengembangan atau Research and Development (R\&D). Model penelitian dan Pengembangan (R\&D) yang digunakan adalah model tressmer dengan tahap-tahap penelitian: tahap preliminary (persiapan dan pendesainan), tahap formative evalution (self evalution, expert review, one to one, small grup,dan field test). Tempat dan

\footnotetext{
${ }^{16}$ Novia Hastuti, Buku Panduan Pratikum SWiSHmax, (Lampung: Politeknik Negeri Lampung), Online: http://aknelt.ac.id/pocontent/uploads/Modul_Desain_Grafis_(Swishmax_1-8).pdf
} 
subyek penelitiannya adalah peserta didik kelas IVG MIN 2 Palembang. Teknik pengumpulan data menggunakan angket dan tes. Angket digunakan untuk mengukur validitas dan kepraktisan media, sedangkan tes digunakan untuk mengukur efektivitas media. Teknik analisis data menggunakan persentase.

\section{HASIL DAN PEMBAHASAN}

\section{Hasil Penelitian}

a. Tahap preliminary (persiapan dan pendesainan)

1) Persiapan

a) Analisis peserta didik

Kesulitan peserta didik dalam proses pembelajaran IPA yaitu: kurang efektif serta kurang menarik media yang digunakan pada proses pembelajaran sehingga mengakibatkan peserta didik kurang termotivasi untuk mengikuti pembelajaran, peserta didik sulit memahami materi yang disampaikan dan pembelajaran juga menjadi monoton. Kelas IV G memiliki jumlah peserta didik sebanyak 39 peserta didik yang terdiri dari 15 perempuan dan 24 laki-laki.

b) Analisis kurikulum

Analisis kurikulum dilakukan untuk mengetahui kurikulum yang digunakan, kompetensi inti, kompetensi dasar, indikator atau tujuan pembelajaran, dan ruang lingkup materi pelajaran Ilmu Pengetahuan Alam diKelas IVG MIN 2 Palembang. Kurikulum yang digunakan adalah kurikulum 2013 dengan pendekatan tematik integratif. Materi atau tema yang ditematikkan dengan mata pelajaran IPA yang diajarkan pada kelas IVG MIN 2 Palembang adalah Tema "Selalu Berhemat Energi" dan Subtema 1 "Sumber Energi".

c) Analisis media pembelajaran

Kekurangan media power point yang telah digunakan guru dalam proses pembelajaran yaitu: terlalu banyak slide sehingga tulisan menjadi kecil-kecil dan mengakibatkan peserta didik sulit memahami materi apa yang telah disampaikan. Salah satu upaya 
AL-MUDARRIS:journal of education, Vol. 2. No. 2 Oktober 2019, ISSN: 2620-5831 (print), ISSN: 2620-4355(online)

DOI: $10.32478 /$ al-mudarris.v\%vi\%i.263

untuk mengatasi kendala tersebut peneliti akan mendesain atau mengmbangkan media pembelajaran tersebut dengan menggunakan software Swishmax.

2) Pendesainan

Pada tahap ini, peneliti mendesain media pembelajaran IPA berbasis Swishmax kelas IV Tema "Selalu Berhemat Energi" dan Subtema 1 "Sumber Energi". Setelah melakukan pendesain, diperoleh media pembelajaran yang sesuai dengan indikator, tujuan, materi, dan mengacu pada mata pelajaran. Hasil pedesainan pada tahap ini berupa prototype awal yang akan di lanjutkan pada tahap self evalution dan Expert review dalam alur Formative evalution.

b. Tahap formative evalution

a. Self evalution

Pada tahap ini peneliti mengkaji ulang dan merevisi sendiri hasil desain media pembelajaran berbasis Swishmax pada tahap preliminary. Peneliti melakukan evaluasi sendiri prototype awal yang telah dikembangkan. Evaluasi ini dilakukan sebagai perbaikan media pembelajaran IPA berbasis Swishmax yang dibuat pada tahap pendesainan.

b. Expert review

Pada tahap ini peneliti merevisi media pembelajaran IPA berbasis Swishmax berdasarkan masukan dan rekomendasi dari para ahli atau validator. Ahli atau validator yang digunakan dalam penelitian ini yaitu: ahli media, ahli bahasa, dan ahli materi.

1) Ahli media

a) Hasil data kuantitatif

Tabel 1. Hasil Data Kuantitatif

\begin{tabular}{|c|l|c|}
\hline No & \multicolumn{1}{|c|}{ Aspek yang dinilai } & Skor \\
\hline 1 & Konten (isi) & 37 \\
\hline 2 & Konstruk/Tampilan & 45 \\
\hline 3 & Penyajian & 11 \\
\hline Jumlah & 93 \\
\hline Rata-Rata (\%) & 84,5 \\
\hline \multicolumn{2}{|l}{ Kategori } & Valid \\
\hline
\end{tabular}


AL-MUDARRIS:journal of education, Vol. 2. No. 2 Oktober 2019, ISSN: 2620-5831 (print), ISSN: 2620-4355(online)

DOI: $10.32478 /$ al-mudarris.v\%vi\%i.263

b) Hasil data kualitatif

Tabel 2. Hasil Data Kualitatif

\begin{tabular}{|c|c|}
\hline Validator & Komentar dan Saran \\
\hline Ahli Media & 1. Perbaiki backgorund \\
& 2. Jangan terlalu banyak tulisan \\
& 3. Gunakan gambar yang kualitasnya bagus, agar \\
& peserta didik dapat mengamati dengan baik dan \\
& cermat terutama pada peserta didik yang \\
& mempunyai gangguan mata yang kurang baik. \\
& 4. Gunakan jenis huruf yang jelas. \\
\hline
\end{tabular}

Tabel 3. Hasil Revisi Validator Ahli Media

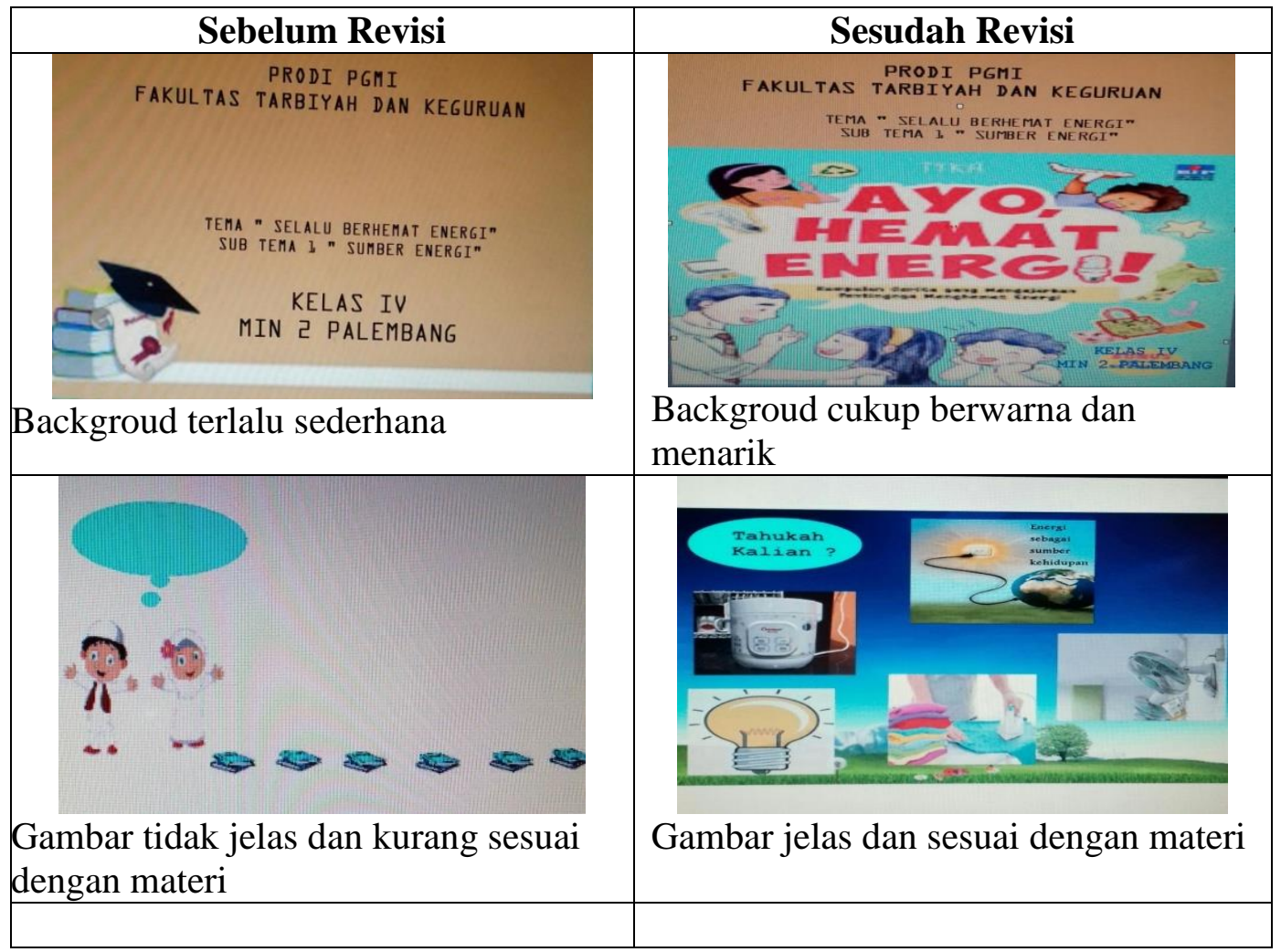


AL-MUDARRIS:journal of education, Vol. 2. No. 2 Oktober 2019, ISSN: 2620-5831 (print), ISSN: 2620-4355(online)

DOI: $10.32478 /$ al-mudarris.v\%vi\%i.263

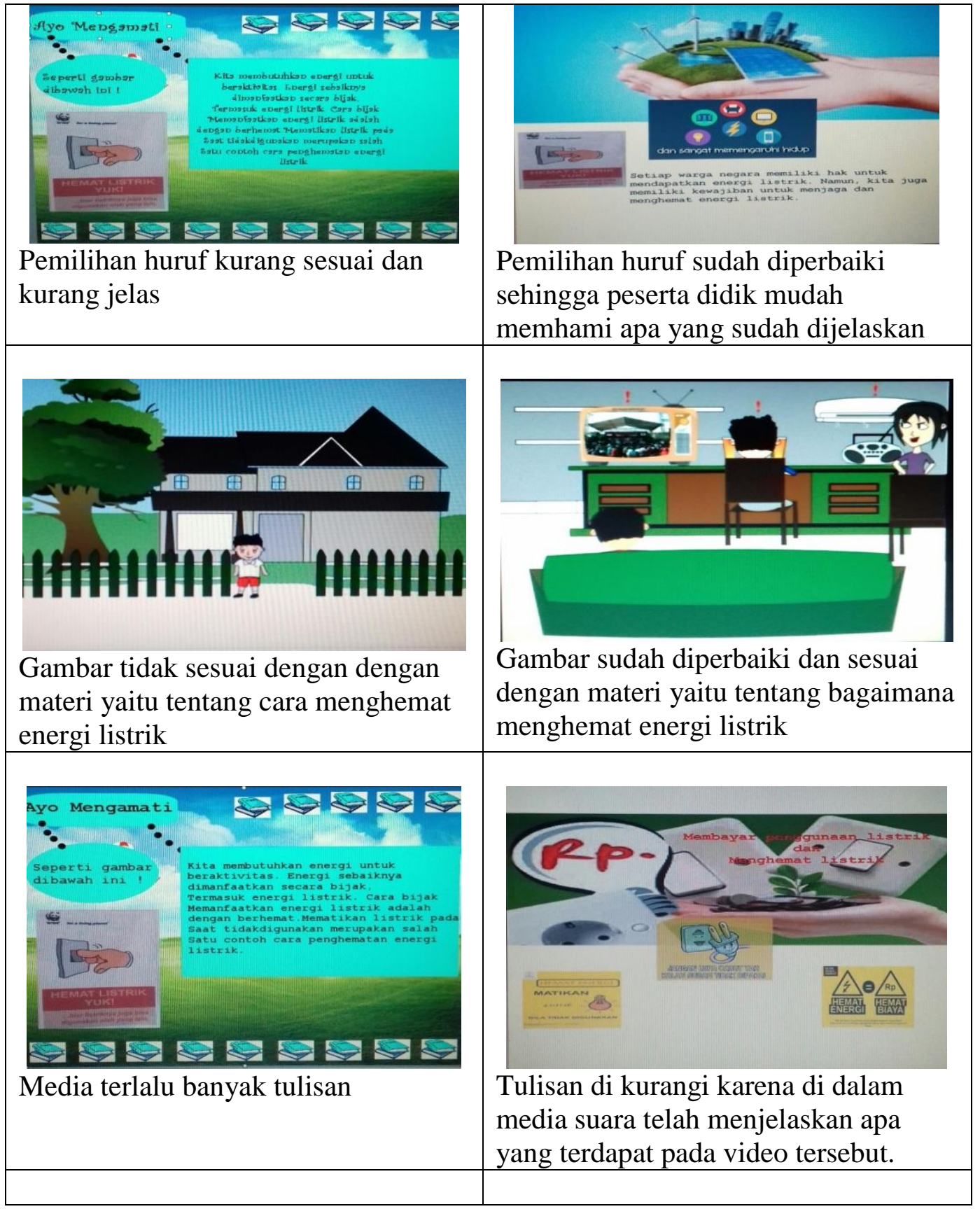


AL-MUDARRIS:journal of education, Vol. 2. No. 2 Oktober 2019, ISSN: 2620-5831 (print), ISSN: 2620-4355(online)

DOI: 10.32478/al-mudarris.v\%vi\%i.263

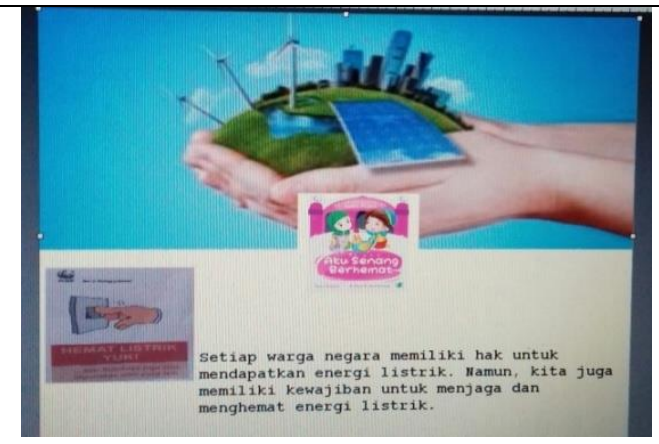

Gambar kurang sesuai dengan penjelasan tentang hak dan kewajiban terhadap energi listik

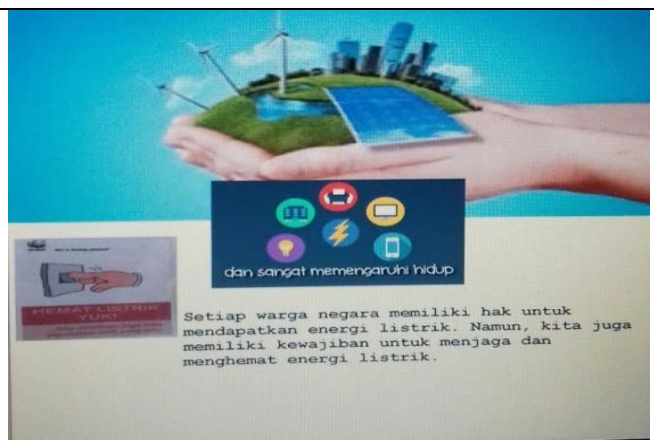

Gambar telah diperbaiki yang sesuai dengan penjelasan hak dan kewajiban terhadap energi listrik

2) Ahli bahasa

a) Hasil data kuantitatif

Tabel 4. Hasil Data Kuantitatif

\begin{tabular}{|c|l|c|}
\hline No & \multicolumn{1}{|c|}{ Aspek yang dinilai } & Skor \\
\hline 1 & Lugas & 21 \\
\hline 2 & Komunikatif & 10 \\
\hline 3 & Dialogis dan Interaktif & 9 \\
\hline 4 & Kesesuaian dengan perkembangan peserta didik & 22 \\
\hline \multicolumn{2}{|l|}{ Jumlah } & 62 \\
\hline \multicolumn{2}{|c|}{ Rata-Rata (\%) } & 82,6 \\
\hline Kategori & Valid \\
\hline
\end{tabular}

b) Hasil data kualitatif

Tabel 5. Hasil Data Kualitatif

\begin{tabular}{|c|l|}
\hline Validator & \multicolumn{1}{|c|}{ Komentar dan Saran } \\
\hline Ahli bahasa & $\begin{array}{l}\text { 1. Rapikan penulisan, sesuaikan pemilihan huruf. } \\
\text { 2. Gunakan EYD yang baik. } \\
\text { 3. Gunakan penggunaan bahasa yang mudah dipahami. }\end{array}$ \\
\hline
\end{tabular}


AL-MUDARRIS:journal of education, Vol. 2. No. 2 Oktober 2019, ISSN: 2620-5831 (print), ISSN: 2620-4355(online)

DOI: $10.32478 /$ al-mudarris.v\%vi\%i.263

\section{Tabel 6. Hasil Revisi Validator Ahli Bahasa}

\begin{tabular}{|l|l|}
\hline Sebelum Revisi & Sesudah Revisi \\
\hline Penulisan tidak rapi, pemilihan huruf \\
kurang sesuai
\end{tabular}


AL-MUDARRIS:journal of education, Vol. 2. No. 2 Oktober 2019, ISSN: 2620-5831 (print), ISSN: 2620-4355(online)

DOI: 10.32478/al-mudarris.v\%vi\%i.263

3) Ahli materi

a) Hasil data kuantitatif

Tabel 7. Hasil Data Kuantitatif

\begin{tabular}{|c|l|c|}
\hline No & \multicolumn{1}{|c|}{ Aspek yang dinilai } & Skor \\
\hline 1 & Format materi & 62 \\
\hline 2 & Isi materi & 19 \\
\hline Jumlah & 81 \\
\hline Rata-Rata (\%) & 90 \\
\hline \multicolumn{2}{|l|}{ Kategori } & Sangat valid \\
\hline
\end{tabular}

b) Hasil data kualitatif

Tabel 8. Hasil Data Kualitatif

\begin{tabular}{|c|l|}
\hline Validator & Komentar dan Saran \\
\hline Ahli Materi & $\begin{array}{l}\text { 1. Sesuaikan materi dengan soal dan diberi gambar } \\
\text { agar soal lebih jelas. }\end{array}$ \\
& $\begin{array}{l}\text { 2. Sesuaikan materi dengan tingkat kemampuan } \\
\text { peserta didik MI/SD. }\end{array}$ \\
& 3. Sesuaikan video dengan kesinambungan materi \\
\hline
\end{tabular}

Tabel 9. Hasil Revisi Validator Ahli Materi

\begin{tabular}{|c|c|}
\hline Sebelum Revisi & \multicolumn{2}{|c|}{ Sesudah Revisi } \\
\hline $\begin{array}{l}\text { Marilah Kita } \\
\text { menyayikan } \\
\text { Lagu Hemat } \\
\text { Energi }\end{array}$ \\
$\begin{array}{l}\text { Tidak harus dengan tulisan ,dapat diisi } \\
\text { dengan suara dan gambar }\end{array}$ \\
\hline \\
\hline \\
\hline
\end{tabular}


AL-MUDARRIS:journal of education, Vol. 2. No. 2 Oktober 2019, ISSN: 2620-5831 (print), ISSN: 2620-4355(online)

DOI: $10.32478 /$ al-mudarris.v\%vi\%i.263

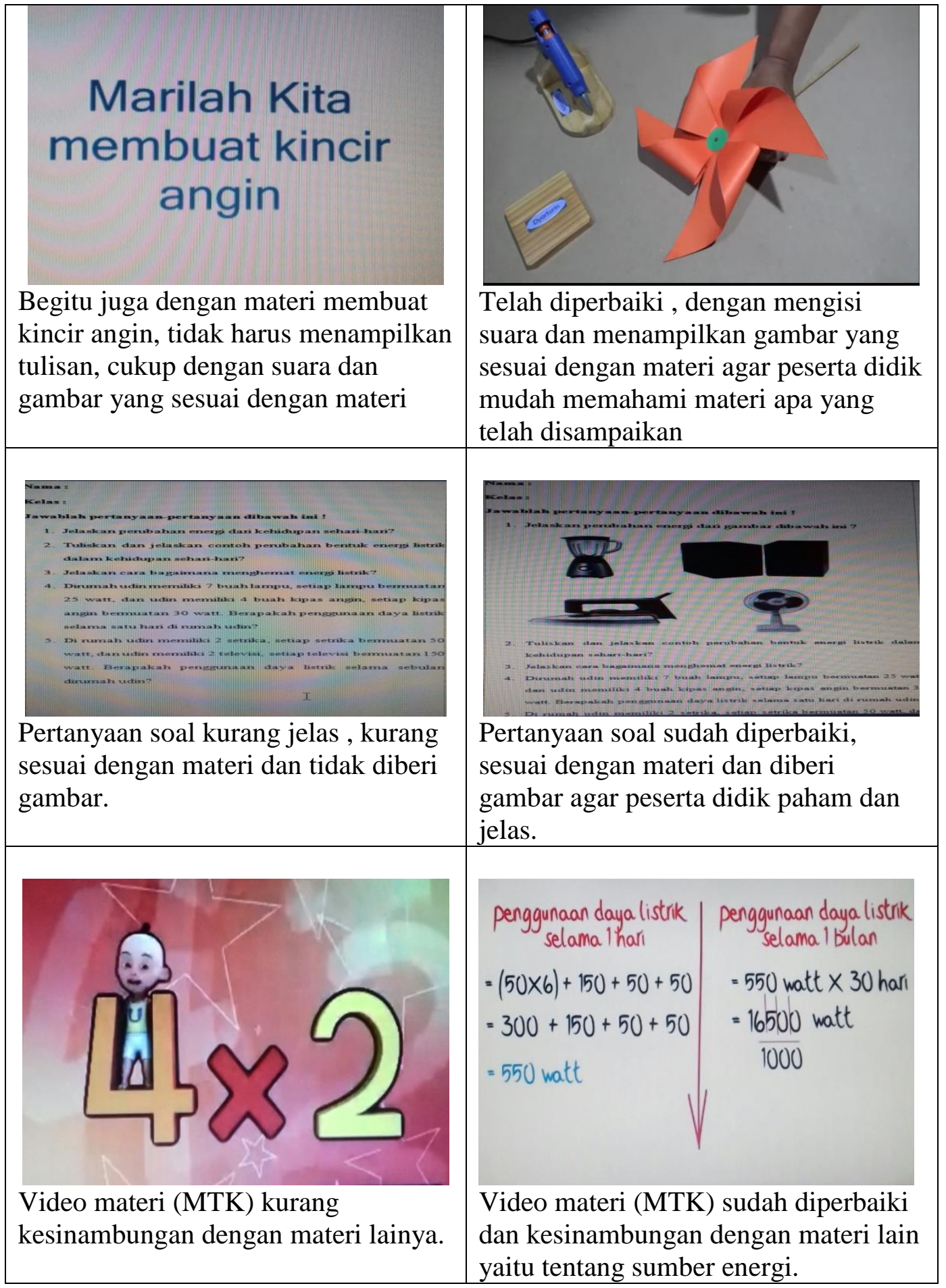




\section{c. One to one}

Pada tahap ini, media pembelajaran berbasis Swishmax yang sudah diperbaiki (revisi) diujicobakan pada 2 (dua) orang peserta didik yang bernama Muhammad Arya Za'faran dan Muhammad Bagas Athaya yang merupakan peserta didik kelas IV G MIN 2 Palembang. Ujicoba ini dilakukan pada tanggal 13 maret 2019.

1) Efektifitas

\section{Tabel 10. Hasil Nilai Evaluasi}

\begin{tabular}{|c|c|c|c|c|c|c|c|}
\hline \multirow[t]{2}{*}{ No } & \multirow{2}{*}{$\begin{array}{l}\text { Nama } \\
\text { Siswa }\end{array}$} & \multicolumn{3}{|c|}{ Nilai } & \multirow[t]{2}{*}{ Jumlah } & \multirow{2}{*}{$\begin{array}{l}\text { Nilai } \\
\text { Akhir }\end{array}$} & \multirow[t]{2}{*}{ KKM $(\geq 66)$} \\
\hline & & Afektif & Kognitif & Psikomotorik & & & \\
\hline 1 & A & 100 & 100 & 100 & 300 & 100 & Tuntas \\
\hline 2 & B & 85 & 95 & 95 & 275 & 92 & Tuntas \\
\hline \multicolumn{2}{|c|}{ Jumlah } & 185 & 195 & 195 & 575 & 192 & 2 \\
\hline \multicolumn{2}{|c|}{ Rata-rata (\%) } & $97,5 \%$ & $92,5 \%$ & $97,5 \%$ & $95,5 \%$ & $96 \%$ & 100 \\
\hline \multicolumn{7}{|c|}{ Kategori } & Sangat Efektif \\
\hline
\end{tabular}

2) Kepraktisan

Tabel 11. Hasil Angket Responden Peserta Didik Tahap One to

One

\begin{tabular}{|c|c|c|}
\hline No & \multicolumn{1}{|c|}{ Nama Siswa } & Jumlah Skor \\
\hline 1 & A & 500 \\
\hline 2 & B & 500 \\
\hline \multicolumn{2}{|c|}{ Jumlah } & 1000 \\
\hline \multicolumn{2}{|c|}{ Rata-Rata (\%) } & $100 \%$ \\
\hline \multicolumn{2}{|c|}{ Kategori } & Sangat Praktis \\
\hline
\end{tabular}

d. Small grup

Pada tahap ini, media pembelajaran berbasis Swishmax pada prototype II hasil revisi pada tahap expert review dan one to one akan diujicobakan pada kelompok kecil yang terdiri dari 6 (enam) orang peserta didik kelas IV G MIN 2 Palembang yang memiliki kemampuan berbeda. Tahap small group dilakukan pada tanggal 14 maret 2019.

1) Efektifitas 
AL-MUDARRIS:journal of education, Vol. 2. No. 2 Oktober 2019, ISSN: 2620-5831 (print), ISSN: 2620-4355(online)

DOI: $10.32478 /$ al-mudarris.v\%vi\%i.263

Tabel 12. Hasil Nilai Evaluasi

\begin{tabular}{|c|c|c|c|c|c|c|c|}
\hline \multirow[t]{2}{*}{ No } & \multirow{2}{*}{$\begin{array}{l}\text { Nama } \\
\text { Siswa }\end{array}$} & \multicolumn{3}{|c|}{ Nilai } & \multirow[t]{2}{*}{ Jumlah } & \multirow{2}{*}{$\begin{array}{l}\text { Nilai } \\
\text { Akhir }\end{array}$} & \multirow[t]{2}{*}{$\overline{\mathrm{KKM}}(\geq 66)$} \\
\hline & & Afektif & Kognitif & Psikomotorik & & & \\
\hline 1 & A & 90 & 100 & 90 & 280 & 93,3 & Tuntas \\
\hline 2 & $\mathrm{~B}$ & 80 & 95 & 100 & 275 & 92 & Tuntas \\
\hline 3 & $\mathrm{C}$ & 90 & 100 & 100 & 290 & 97 & Tuntas \\
\hline 4 & $\mathrm{D}$ & 80 & 95 & 90 & 265 & 88 & Tuntas \\
\hline 5 & $\mathrm{E}$ & 100 & 100 & 100 & 300 & 100 & Tuntas \\
\hline 6 & $\mathrm{~F}$ & 85 & 95 & 100 & 280 & 93 & Tuntas \\
\hline & Jumlah & 525 & 585 & 580 & 1690 & 563,3 & 6 \\
\hline Rata & ata (\%) & $87,5 \%$ & $97,5 \%$ & $96,6 \%$ & $93,8 \%$ & $93,8 \%$ & $100 \%$ \\
\hline \multicolumn{7}{|c|}{ Kategori } & Sangat Efektif \\
\hline
\end{tabular}

2) Kepraktisan

Tabel 13. Hasil Angket Responden Peserta Didik Tahap Small Group

\begin{tabular}{|c|c|c|}
\hline No & Nama & Jumlah Skor \\
\hline 1 & A & 500 \\
\hline 2 & B & 500 \\
\hline 3 & C & 500 \\
\hline 4 & D & 500 \\
\hline 5 & E & 500 \\
\hline 6 & F & 500 \\
\hline \multicolumn{2}{|c|}{ Jumlah } & 3000 \\
\hline \multicolumn{2}{|c|}{ Rata- Rata (\%) } & $100 \%$ \\
\hline \multicolumn{2}{|c|}{ Kategori } & Sangat Praktis \\
\hline
\end{tabular}

\section{e. Field test}

Pada tahap ini, media pembelajaran berbasis Swishmax prototype III di ujicobakan pada peserta didik kelas IVG MIN 2 Palembang yang telah dipilih sebagai subyek penelitian. selanjutnya akan diperoleh hasil jawaban evaluasi atau tes akhir yang digunakan untuk melihat kefektifan dan angket respon peserta didik yang digunakan untuk melihat kepraktisan media pembelajaran berbasis Swishmax pada mata pelajaran ilmu pengetahuan alam kelas IV MIN 2 Palembang. Penelitian ini dilaksanakan di MIN 2 Palembang, sumatera selatan dengan subjek penelitian peserta didik kelas IV $G$ yang berjumlah 39 orang, dengan rincian 24 laki-laki dan 15 perempuan. 
Proses pengambilan data ( field test) pada penelitian ini dilakukan pada tanggal 15 maret 2019.

1) Efektifitas

Tabel 14. Rekapulasi Penilaian Evaluasi

\begin{tabular}{|l|c|c|c|c|c|c|}
\hline \multirow{2}{*}{ Indikator } & \multicolumn{3}{|c|}{ Nilai Hasil } & Jumlah & $\begin{array}{c}\text { Nilai } \\
\text { Akhir }\end{array}$ & KKM $(\geq 66)$ \\
\cline { 2 - 4 } & $\mathrm{A}$ & $\mathrm{K}$ & $\mathrm{P}$ & & 39 \\
\hline Jumlah & 3554 & 3624 & 3586 & 11069 & 3498 & $100 \%$ \\
\hline Rata-Rata \% & $91 \%$ & $93 \%$ & $92 \%$ & $95 \%$ & $95 \%$ & Sangat Efeketif \\
\hline \multicolumn{7}{|c|}{ Kategori }
\end{tabular}

2) Kepraktisan

Tabel 15. Hasil Angket Respons Peserta Didik Tahap

Field Test

\begin{tabular}{|l|c|c|}
\hline \multicolumn{1}{|c|}{ Indikator } & Jumlah & Rata-Rata \\
\hline Jumlah & 19500 & 3900 \\
\hline Rata-Rata (\%) & $100 \%$ & $100 \%$ \\
\hline Kategori & Sangat Praktis & Sangat Praktis \\
\hline
\end{tabular}

\section{Pembahasan}

a. Validitas Pengembangan Media Pembelajaran Berbasis Swishmax Pada Mata Pelajaran Ilmu Pengetahuan Alam Kelas IV G MIN 2 Palembang

Prototype dari proses revisi berdasarkan saran dan komentar validator yang dilakukan pada tahap expert review diperoleh media pembelajaran berbasis Swishmax pada materi Ilmu Pengetahuan Alam kelas IV G MIN 2 Palembang yang dikembangkan menggunakan metode tressmer dapat dikategorikan valid dengan melihat lembar angket validasi pakar/ahli. Untuk mengembangkan media pembelajaran berbasis Swishmax yang valid diperlukan pengembangan yang sesuai dengan teori pembelajaran yang digunakan. Untuk melihat kevalidan media pembelajaran berbasis Swishmax yaitu dengan melihat skor serta komentar dan saran oleh para pakar/ahli seperti dibawah ini: 
AL-MUDARRIS:journal of education, Vol. 2. No. 2 Oktober 2019, ISSN: 2620-5831 (print), ISSN: 2620-4355(online)

DOI: $10.32478 /$ al-mudarris.v\%vi\%i.263

Tabel 16. Rekapulasi Hasil Validasi

\begin{tabular}{|c|l|l|c|c|c|}
\hline No & \multicolumn{1}{|c|}{ Validator } & \multicolumn{1}{|c|}{ Expert } & $\begin{array}{c}\text { Jumlah } \\
\text { Skor }\end{array}$ & $\begin{array}{c}\text { Rata- } \\
\text { Rata }\end{array}$ & Kategori \\
\hline 1 & Amir Hamzah, M.Pd. & Ahli Media & 93 & 84,5 & Valid \\
\hline 2 & Hani Atus Sholikhah, M.Pd. & Ahli Bahasa & 62 & 82 & Valid \\
\hline 3 & Hj. Nurhastin, M.Pd. & Ahli Materi & 81 & 90 & Valid \\
\hline
\end{tabular}

Berdasarkan tabel 16 hasil angket validator di atas diperoleh rata-rata dengan kategori valid. Maka media pembelajaran berbasis Swishmax pada mata pelajaran Ilmu Pengetahuan Alam kelas IV G MIN 2 Palembang dinyatakan valid dan media dapat digunakan untuk uji coba di lapangan.

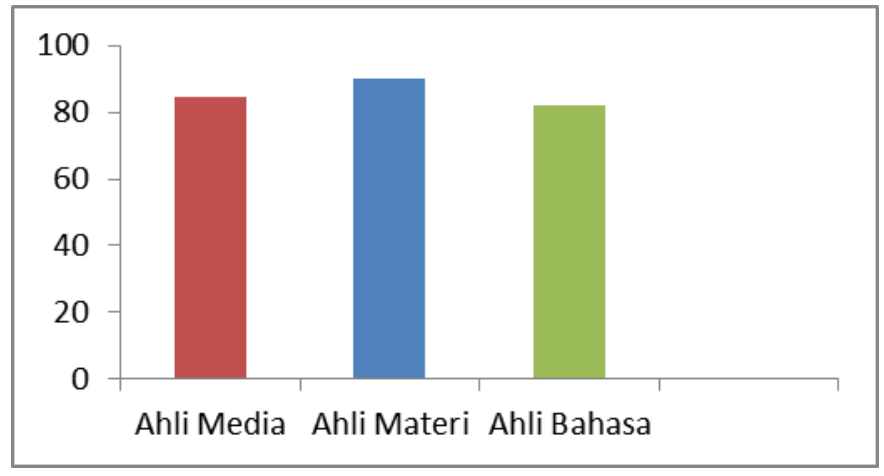

\section{Gambar 1. Grafik Rekapulasi Hasil Validasi}

Berdasarkan gambar grafik hasil rekapulasi validator di atas dapat disimpulkan bahwa nilai rata-rata tertinggi validator adalah ahli materi sebesar 90, sedangkan nilai rata-rata terendah validator adalah ahli bahasa sebesar 82 .

Tabel 17. Hasil Komentar dan Saran Validator

\begin{tabular}{|c|c|}
\hline Validator & Komentar dan Saran \\
\hline Amir Hamzah, M.Pd.I & 1. Perbaiki backgorund \\
& 2. Jangan terlalu banyak tulisan \\
& 3. Gunakan gambar yang kualitasnya \\
& bagus, agar peserta didik dapat \\
& mengamati dengan baik dan cermat \\
& terutama pada peserta didik yang \\
& mempunyai gangguan mata yang \\
\hline
\end{tabular}




\begin{tabular}{|l|l|}
\hline & kurang baik. \\
& \\
\hline Hani Atus Sholikhah, & $\begin{array}{l}\text { 1. Gunakan jenis huruf yang jelas. } \\
\text { 2. Rapikan penulisan, sesuaikan } \\
\text { pemilihan huruf. } \\
\text { 3.Pd Gunakan EYD yang baik. } \\
\text { 4. Gunakan penggunaan bahasa yang } \\
\text { mudah dipahami. }\end{array}$ \\
\hline Hj. Nurhastin, M.Pd & $\begin{array}{l}\text { 1. Sesuaikan materi dengan soal dan } \\
\text { diberi gambar supaya soal lebih jelas. } \\
\text { 2. Sesuaikan soal-soal yang sesuai dengan } \\
\text { tingkat kemampuan peserta didik } \\
\text { MI/SD. video } \\
\text { 3. Sesuaikan dengan } \\
\text { kesinambungan materi. }\end{array}$ \\
\hline
\end{tabular}

Berdasarkan hasil data validasi dari ahli/pakar baik hasil data kuantitatif maupun hasil data kualitatif, dapat disimpulkan bahwa pengembangan media pembelajaran IPA berbasis Swishmax di kelas IV MIN 2 Palembang dinyatakan valid.

\section{b. Kepraktisan Pengembangan Media Pembelajaran Berbasis Swishmax Pada Mata Pelajaran Ilmu Pengetahuan Alam Kelas IV G MIN 2 Palembang}

Responden untuk mengukur kepraktisan media pembelajaran yang dikembangkan dalam penelitian ini adalah peserta didik. Hal ini dilakukan karena guru yang mengajar dalam penelitian ini adalah peneliti sendiri. Untuk menghindari subyektifitas penilaian kepraktisan media yang digunakan, maka data diambil bukan dari guru yang mengajar tetapi dari responden peserta didik kelas IV G MIN 2 
AL-MUDARRIS:journal of education, Vol. 2. No. 2 Oktober 2019, ISSN: 2620-5831 (print), ISSN: 2620-4355(online)

DOI: $10.32478 /$ al-mudarris.v\%vi\%i.263

Palembang yang telah mengikuti pembelajaran IPA dengan menggunakan media pembelajaran berbasis Swishmax.

Prototype dari proses revisi berdasarkan hasil angket peserta didik yang dilakukan pada tahap one to one, small group, dan field test diperoleh media pembelajaran berbasis Swishmax pada materi Ilmu Pengetahuan Alam kelas IV G MIN 2 Palembang yang dikembangkan menggunakan metode Tressmer dapat dikategorikan sangat praktis dengan melihat lembar angket responden peserta didik berikut ini.

Tabel 18. Rekapulasi Angket Responden Peserta didik

\begin{tabular}{|c|c|c|c|}
\hline No. & Tahap & Jumlah & Kategori \\
\hline 1. & One To One & 100 & Sangat Praktis \\
\hline 2. & Small Group & 100 & Sangat Praktis \\
\hline 3. & Field Test & 100 & Sangat Praktis \\
\hline
\end{tabular}

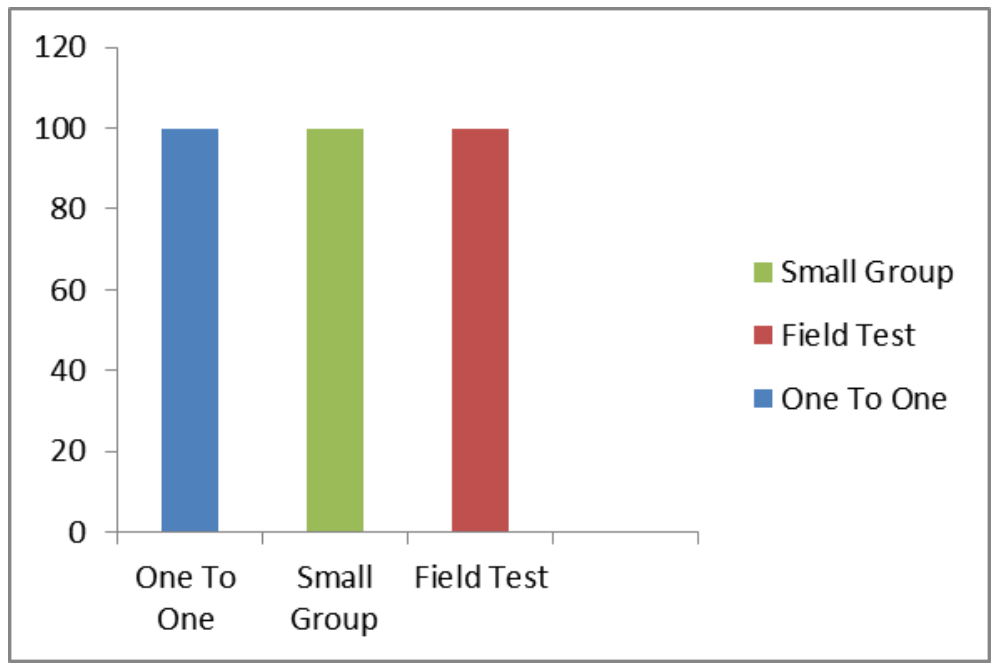

\section{Gambar 2. Grafik Rekapulasi Angket Responden Peserta Didik}

Berdasarkan tabel hasil lembar angket responden peserta didik dan gambar grafik hasil rekapulasi angket responden peserta didik pada tahap one to one, small group, dan field test rata-rata sebesar 100 dan dikategorikan sangat praktis. Berdasarkan data tersebut, maka dapat 
disimpulkan bahwa pengembangan media pembelajaran IPA berbasis Swishmax di kelas IV MIN 2 Palembang dinyatakan sangat praktis.

\section{c. Efektivitas Pengembangan Media Pembelajaran Berbasis Swishmax Pada Mata Pelajaran Ilmu Pengetahuan Alam Kelas IV G MIN 2 Palembang}

Prototype dari proses revisi berdasarkan hasil evaluasi atau tes akhir dilakukan pada tahap one to one, small group, dan field test diperoleh media pembelajaran berbasis Swishmax pada materi Ilmu Pengetahuan Alam kelas IV G MIN 2 Palembang yang dikembangkan menggunakan metode tressmer dapat dikategorikan sangat efektif dengan melihat lembar hasil evaluasi peserta didik setelah mengikuti proses pembelajaran. Untuk melihat keefektifan media pembelajaran berbasis Swishmax dapat dilihat dengan hasil evaluasi peserta didik setelah mengikuti proses pembelajaran pada tabel di bawah ini.

Tabel 19. Rekapulasi Evaluasi Peserta Didik

\begin{tabular}{|c|c|c|c|c|c|}
\hline No & Tahap & Jumlah & Rata-Rata & Tuntas (\%) & Kategori \\
\hline 1 & One To One & 192 & 96 & $96 \%$ & Sangat Efektif \\
\hline 2 & Small Group & 563,3 & 93,8 & $93,8 \%$ & Sangat Efektif \\
\hline 3 & Field Test & 3498 & 95 & $95 \%$ & Sangat Efektif \\
\hline
\end{tabular}

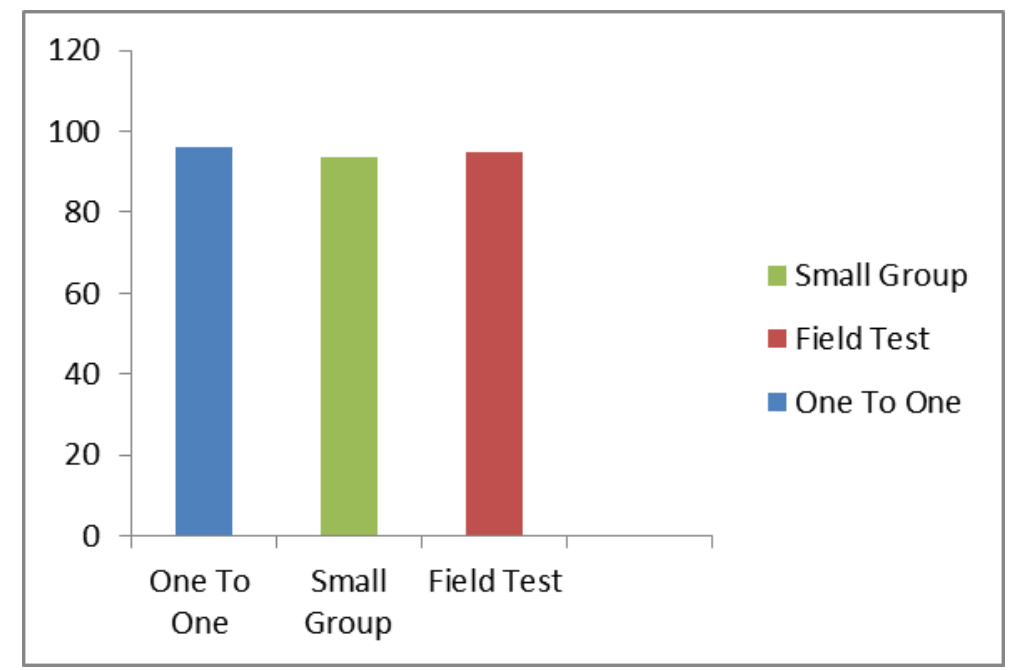


AL-MUDARRIS:journal of education, Vol. 2. No. 2 Oktober 2019, ISSN: 2620-5831 (print), ISSN: 2620-4355(online)

DOI: $10.32478 /$ al-mudarris.v\%vi\%i.263

\section{Gambar 3. Grafik Rekapulasi Evaluasi Peserta Didik}

Berdasarkan tabel hasil data evaluasi peserta didik di atas, maka dapat disimpulkan bahwa pengembangan media pembelajaran IPA berbasis Swishmax di kelas IVG MIN 2 Palembang dinyatakan sangat efektif baik pada tahap skala kecil (one to one dan small group) maupun secara keseluruhan (field test).

\section{E. KESIMPULAN}

1. Pengembangan media pembelajaran Ilmu Pengetahuan Alam berbasis Swishmax di Kelas IVG MIN 2 Palembang dapat dikategorikan valid. Hal ini ditunjukkan dari perolehan skor validasi ahli media sebesar 84,5, ahli bahasa 82, dan ahli materi 90

2. Tingkat kepraktisan penerapan pengembangan media pembelajaran Ilmu Pengetahuan Alam berbasis Swishmax di Kelas IVG MIN 2 Palembang sangat praktis. Hal ini dapat diketahui dari perolehan rata-rata skor angket sebesar 100 pada tahap field test.

3. Efektivitas pengembangn media pembelajaran Ilmu Pengetahuan Alam berbasis Swishmax di Kelas IVG MIN 2 Palembang sangat efektif. Hal tersebut diketahui dari tingkat ketuntasan belajar peserta didik secara klasikal mencapai $95 \%$ pada tahap field test.

\section{F. DAFTAR PUSTAKA}

Aquami. Muhamad Afandi. Andi Putra Sairi. Pengembangan Media Pembelajaran Berbasis ICT Menggunakan Macromedia Flash Pada Mata Pelajaran IPA MI/SD. Al-Mudarris Journal of Education. Volume 2. Nomor 1. April 2019. https://doi.org/10.32478/al-mudarris.v2i1.194 
Cecep Kustandi. 2011. Media Pembelajaran Manual dan Digital. Bogor: Ghalia Indonesia.

Deni Erlansyah. Pemanfaatan Multimedia Interaktif Konsep Usaha dalam Pelajaran Fisika Berbasis Teknologi Informasi. Jurnal Ilmiah MATRIK. Volume 17. Nomor. 3. Desember 2015.

Munir. 2012. Pembelajaran Jarak Jauh Berbasis Teknologi Informasi dan Komunikasi. Bandung: Alfabeta.

Novia Hastuti, Buku Panduan Pratikum SWiSHmax, (Lampung: Politeknik Negeri Lampung), Online: http://aknelt.ac.id/pocontent/uploads/Modul_Desain_Grafis_(Swishmax_1-8).pdf

Nunung Dwi Setiyorini. Pembelajaran Kontekstual IPA Melalui Outdoor Learning di SD Alam Ar-Ridho Semarang. AlMudarris Journal of Education. Volume 1. Nomor 1. April 2018. https://doi.org/10.32478/al-mudarris.v1i1.97

Pujiriyanto. 2012. Teknologi Pengembangan Media dan Pembelajaran. Jakarta: Raja Grafindo.

Yeka Hendriani. Vera Irma Delianti. Lativa Mursyida. Persepsi Penggunaan SWiSHmax untuk Pengembangan Media Pembelajaran Oleh Guru Sekolah Dasar di Gugus 3 Kamang Magek Kabupaten Agam. Jurnal Teknologi Informasi dan Pendidikan. Volume 10. Nomor 3. Oktober 2017. 